Andreász Kosztopulosz - Éva Kuruczleki (eds.) (2020): The Challenges of Analyzing Social and Economic Processes in the 21st Century. University of Szeged Faculty of Economics and Business Administration, Szeged, https://doi.org/10.14232/casep21c.2

\title{
Autonomous cars and responsible innovation
}

\author{
Miklós Lukovics - Bence Zuti - Erik Fisher - Béla Kézy
}

\begin{abstract}
Digitalization, a dominant megatrend in today's global world, offers numerous intriguing technological possibilities. Out of these novelties, self-driving cars have rapidly come to be a primary focus; the literature categorizes them as a radical innovation due to the possibility that the mass adoption of self-driving cars would not only radically change everyday life for members of industrialized societies, but calls into question the infrastructural, legal, and social ordering of towns and numerous aspects of transportation in the societies that adopt them. Meanwhile, the results of several international surveys with large samples show that public opinion of self-driving cars is ambivalent, indicating parallel signals of enthusiasm and concern. The aim of this paper is to develop key components of a general strategy for addressing the societal challenges associated with self-driving cars as identified in international surveys and relevant literature and using the framework of responsible innovation.
\end{abstract}

Keywords: fourth industrial revolution, autonomous car, responsible innovation

\section{Introduction}

Recently, commentators have heralded what is being termed "the fourth industrial revolution," which is defined as a process that emphasizes the role of systems and networks based on information and communications technology (Kovács 2017a), and which they anticipate to reshape the global division of labor (Lengyel et al. 2016). Widespread and accessible internet, artificial intelligence and machine learning, and also green energy make up the foundation of the corresponding industry 4.0. Its key elements may in turn include physical (autonomous motorcars, 3D printing, advanced robots), digital ("The Internet of Things") and biological (gene technology) factors (Kuruczleki et al. 2016, Prisecaru 2016). As with similar revolutions heralded in the recent past (e.g., nanotechnology; cf. Kennedy 2008), the fourth industrial revolution promises considerable opportunities aided by radical innovations and global, fastpaced change that affects most aspects of everyday life.

A definition of breakthrough technologies has been created by OECD (2015, p. 3): "The definition of breakthrough technologies adopted is rather wide and include new, fast-growing, radical technologies that either introduce new product or process with very high market potential, or that make existing established technologies rapidly obsolete".

The autonomous vehicle is one example of the radical innovations or breakthrough technologies of the fourth industrial revolution. Such vehicles would be completely automated and maintain control under all circumstances; i.e. they would be able to operate without human intervention. In contrast to automated metro operation that is increasingly visible on roadways today, autonomous cars are not 
track-based; and since the final objective is complete autonomy, artificial intelligence is expected to play a considerably more significant role in these vehicles. There are two aspects associated with this innovation worth noting: i) according to the visions and forecasts, this innovation has the capacity to fundamentally shape the future of humanity; and ii) it is in a far more advanced stage than many in the public may think, as final-phase tests are currently under way on the public roads of 73 cities.

At the same time, this radical innovation significantly divides the opinions of global society. For instance, the widespread adoption of autonomous vehicles will bring about changes in the value chain of the automotive industry and related sectors, in the ways people relate to transport vehicles, and also in everyday transport. Thus, beyond the issue of the reliability of autonomous vehicles, such broader aspects raise a host of social, ethical, environmental and economic risks, which are as of yet unaddressed by their promoters and designers.

Such broader societal issues are closely related to the area of responsible research and innovation, which aims to minimize the unintended effects of research, development and innovation processes in early stages. Accordingly, the objective of this research is to explore the most debated societal risks of the autonomous vehicle as an example of radical innovation, and to offer solutions utilizing the framework of responsible innovation.

In the first part of the paper, we shall address digitalization, one of the key capabilities of the fourth industrial revolution. We shall continue by defining nontrack-based autonomous vehicles, describing their social reception, and outlining the positive vision for the future as well as the possible risks related to these vehicles. In the second part of the paper, we shall offer possible solutions for addressing the likely risks associated with non-track-based autonomous vehicles using the framework and concepts of responsible innovation.

\section{The Fourth Industrial Revolution: The Growing Use of Digitalization}

Industry 4.0 is projected to have considerable influence not only over production processes in certain industry sectors, but also over the lives of individuals (Schmidt et al. 2015). Given the sweeping nature of its visions, it is not surprising that the definitions of Industry 4.0 show considerable diversity (see Davies 2015, Kovács 2017a, Nagy 2017, Pfolh et al. 2015, Schuh et al. 2017, Schmidt et al. 2015, or Smit et al. 2016). In an effort to be comprehensive, this study will adopt the definition by Pfolh et al. (2015, p. 37), according to which "Industry 4.0 is the sum of all disruptive innovations derived and implemented in a value chain to address the trends of digitalization, autonomization, transparency, mobility, modularization, networkcollaboration and socializing of products and processes."

Recent technological innovations are closely linked to digitalization. Digitalization is a self-catalyzing process that assigns a virtual projection to all aspects of life. From an economic perspective, it provides process and organization development opportunities to stakeholders; and from a social aspect, it enables continuous exchange of data between individuals and devices supported by infocommunication infrastructure and the internet (Capgemini 2011, Krishna 2017, OW 
2014). At present, we see the emergence of a socio-economic environment in which smart devices constantly communicate with each other and customers interacting with the material and the virtual realms in a parallel fashion (Hwang 2016, Kagermann et al. 2013, Pfolh et al. 2015). A large part of people's lives is present in the digital space whose online presence and connectedness with smart devices has dramatically grown over the past decade (OW 2014).

Considering contemporary advances in research related to Artificial Intelligence is inevitable when it comes to the discussion about autonomous vehicles. With the use of AI, autonomous vehicles will be able to interpret metrics related to their surroundings, understand traffic and environmental conditions. Eventually, this mass of information acts as an input to the driving-related decision making of autonomous cars, hence aiming to replicate or even exceed the precision of human driver actions. One of the ultimate goals is to significantly reduce car accidents in traffic, however there are concerns regarding the ethical aspects (e. g. the Trolley Problem) and the trustworthiness of AI systems (Cunneen et al. 2019, Nascimento et al. 2019, OECD 2019). AI is currently in an infant state, providing researchers and experts with a multitude of questions and challenges to consider (OECD 2019). However, the expectation is that AI will ultimately add significant value to society and economy and offer a great potential, hence the research and deep level understanding of AI bears great significance (Cunneen et al. 2019).

In short, the autonomous vehicle exemplifies digitalization, the relevance of $\mathrm{AI}$ and is categorized by the literature as a radical innovation, which refers to the idea that the mass adoption of such cars would radically alter everyday life, the structure of urban environments, and numerous aspects of transportation, insurance, labor, and regulation - among other things.

\section{Autonomous Vehicles: Emergence, Public Opinion and Risks}

As a result of several decades of research and development (R\&D), conventional cars previously entirely under human control are thought to be approaching full autonomy and can be regarded as self-driving (Giffi et al. 2017, Yeomans 2014). Digitalization allows recent cars to be equipped with an array of different sensors that are meant to make driving, transportation and other vehicle-related industrial activities safer and more technologically advanced (SMMT 2017a, SMMT 2017b, Yeomans 2014). The terms "self-driving," "autonomous" and "driverless" are not only applied to cars, but also to drones, trains, buses, spacecraft and other freight vehicles (Yeomans 2014).

In this study, we focus on autonomous vehicles (defined in Chapter 3.1) as examples of radical innovation that could affect large populations throughout the industrialized world; importantly, radical innovation is characterized by immense uncertainty, complexity, and moral and sociological ambivalence (Goorden et al. 2008). 


\subsection{Autonomous Vehicles}

The definition of autonomous vehicles (including non-track-based autonomous buses and lorries) is based on the meaning of the term "autonomous", which is better understood with further insight into the levels of automation. Definition of these levels may vary with each authority; the three leading categorization systems for levels of automation are those of the NHTSA (National Highway Traffic Safety Administration), the SAE (Society of Automotive Engineers), in the United States, and the German BASt (Bundesanstalt für Straßenwesen). In this paper, we shall review the system of the SAE, as this is the most detailed in defining the levels of automation. SAE defines the following levels of automation (Glancy 2016, ITF 2015):

- Level 0: No automation. The vehicle is entirely in the hands of the human driver who exercises full control.

- Level 1: Driver assistance. Driver assistance systems are able to provide specific information for the driver and are also able to take over tasks related to either acceleration/deceleration or steering, but not both. The vehicle remains under human control.

- Level 2: Partial automation. Driver assistance systems are able to take over tasks related to both acceleration/deceleration and steering, even simultaneously. Still, the vehicle remains under human control.

- Level 3: Conditional automation. The vehicle's automated driving system is able to take control of dynamic driving tasks (lateral and longitudinal control), yet the system assumes that the human driver is capable of responding and regaining control.

- Level 4: High automation. As with the previous level, the vehicle's automated driving system is able to take over and maintain control of dynamic driving tasks (there is lateral and longitudinal control), even when the human driver is unable to regain control.

- Level 5: Full automation. The vehicle's automated driving system is able to maintain control under all conditions, i.e. the system is able to drive without any human intervention.

Throughout the study we shall define autonomous vehicles as fully automated vehicles that fall into the category of Level 5.

\subsection{Autonomous Vehicles: Broad Societal Implications}

The widespread adoption of autonomous vehicles could bring about the largest, fastest and the most profound changes in the history of mobility.

A number of predictions place the worldwide adoption of autonomous vehicles early on or at the end of the current decade (Wadud et al. 2016), or in the first half of the next one; Arbib and Seba (2017) calculate that by 2030, 95\% of passenger miles in the United States will be served by autonomous vehicles run by fleet operators. If made possible by regulations, people - instead of using their own cars and especially in urban traffic - may use transportation as a service, which would be 
cheaper than maintaining a car - without considerable compromises regarding convenience (Keeney 2017, Litman 2017); but it may even complement railway transportation as a viable alternative for short trips between railway stations and final destinations (Yap et al. 2016). If such a regime is adopted, some of the considerable changes in daily life would likely include the following (Arbib-Seba 2017, FagnantKockelman 2015, Hohenberger et al. 2016, Keeney 2017, Litman 2017):

- Implications for local economies. Less expensive transportation results in greater household savings that may partly be channeled to local businesses as extra spending. Although municipal revenues (parking fees, vehicle tax) may decline, this will probably be counterbalanced by a reduction in the maintenance and development costs of the road infrastructure and parking system, which will be used by fewer cars. Time spent in autonomous vehicles can also be put to other uses - even work (Yap et al. 2016). In addition, autonomous vehicles may appear in the production sector (fork-lift trucks, lorries), which may reduce turn times, and also downtime during long distance trips with the disappearance of mandatory resting periods (FagnantKockelman 2015).

- Use of space, urban environment. With the proliferation of autonomous vehicles, transportation is predicted to become a service in everyday life, thus liberating significant amounts of valuable city space. While nowadays an average car spends $96 \%$ of its lifetime parking, this time is expected to drop to below $50 \%$ for autonomous cars run by fleet operators. New community spaces, parks may be established, but former parking spaces may also be used to ease the pressing housing shortage. In summary, cities would become less crowded, and also more walkable, safer and livable.

- Environmental and health implications. Carsharing based on electric autonomous vehicles would reduce traffic-related air emissions to a fraction of its current rate, which, in turn, would improve air quality - as well as the quality of life - in cities. Wadud et al. (2016), however, note that the emergence of electric vehicles may also result in a reduced demand for conventional vehicles, changed transportation habits (e.g. carsharing), thus a smaller number of cars on the roads, which would again lead to reduced emissions and falling fuel demand. Eliminating human reaction time as a limiting factor would speed up motorway traffic, which, in turn, would also reduce fuel consumption as well as the burden on the environment. Autonomous cars are supposedly safer than human-driven cars, and a considerable drop in the number of car accidents would be expected.

- Access. Universal access to mobility is a key function of transportation systems. Built on autonomous vehicles, door-to-door services may grant mobility to even those who cannot afford to maintain a car, or those who cannot drive (the elderly or handicapped people), and also to those for whom public transportation cannot offer a solution due to the location of their residence. 
Despite the considerable advantages currently predicted by its promoters, public opinion is not similarly unanimous. In the past few years, a large number of largescale studies have been published that suggest reliable trends in public opinion of autonomous vehicles. Most of these studies were conducted in the United States, but many also include international surveys. We present the findings of these studies in the next section.

\subsection{Autonomous Vehicles: Public Opinion Surveys}

Schoettle and Sivak (2014) conducted a survey involving a total of 1533 people in three countries pioneering in autonomous vehicle technology: The United States, the United Kingdom and Australia. These surveys yielded mixed results: most respondents had a positive opinion of autonomous vehicle technology. Almost 60\% of respondents had a very positive or positive general opinion on autonomous cars; $30 \%$ had a neutral opinion, and only slightly over $10 \%$ voiced a negative opinion. The respondents expressed bold expectations regarding the benefits of autonomous cars: these include fewer accidents and reduced severity of accidents; less traffic congestion, shorter travel times, a reduced environmental burden and lower insurance rates. However, the majority of respondents also expressed serious concern: the option "I am very concerned" was marked by $46.8 \%$ for problems resulting from system failures, $34.7 \%$ for uncertainty regarding legal liability, 35.2\% for hacker attacks, $30.2 \%$ for data privacy (location and destination tracking), $33.5 \%$ for interacting with non-autonomous vehicles, $37 \%$ for interacting with pedestrians and bicyclists; and they were also concerned about system performance in poor weather $(28 \%)$ and about the system getting confused by unexpected situations (32.4\%).

A survey by Kyriakidis et al. (2015) is based on the largest sample surveyed so far on the topic of autonomous cars. Involving 5,000 people from 109 countries, their survey revealed that the majority of respondents were concerned about software hacking and misuse, and also about legal issues and safety. In addition, the positive attitude of respondents was related to the tasks they could engage in when travelling in an autonomous vehicle: checking emails, making phone calls, watching movies, reading, resting, or observing the scenery.

The survey conducted by the AAA (2017) is especially important for our study, as it was conducted in a time when one could actually meet autonomous vehicles in the streets due to the advanced stages of testing. In this study, 1012 people were involved from the United States, a country in which pedestrians may have already seen autonomous vehicles on the streets. In light of this fact it is remarkable that among the respondents who think that the introduction of autonomous vehicles is imminent, $66 \%$ would be afraid to ride in an autonomous vehicle, $19 \%$ would trust the vehicle and $4 \%$ are unsure. In addition, 54\% would still feel less safe sharing the road with autonomous vehicles while driving a regular car. $34 \%$ feel it makes no difference, $10 \%$ would feel safer sharing the road with autonomous vehicles and $2 \%$ are unsure. It is interesting that 59\% want autonomous technology in their next car.

In summary, research findings clearly indicate that there is a positive anticipation towards the emergence of autonomous vehicles in society, which is also 
surrounded by a shroud of concern, unease and uncertainty. It is also a clear trend that these concerns are linked exclusively to fully autonomous vehicles (Level 5, as discussed in Chapter 3.1), yet respondents seem to accept high levels of automation (Level 4) without concern, as long as they have control over the driving process. Most studies also show that there is limited amount of information available on fully autonomous vehicles, and also that respondents find this technology immature and feel the need for additional testing.

\subsection{Autonomous Vehicles: Identified Risks}

With the introduction of autonomous vehicles - as with any new technology - one may identify a wide range of risks, some of which are directly derived from the concerns revealed by studies on the public opinion on autonomous vehicles. These risks can be classified into five larger categories: technological, environmental, sectorial, ethical and governance risks.

Ethical risks are some of the most strongly emphasized groups of the risks identified, since the most emphasized question is how the autonomous vehicle system reacts to a suspected accident situation (Blyth et al. 2015, Bonnefon et al. 2016). It is important to realize that it is not the autonomous vehicle engine and mechanics that provide a solution for these dangerous situations, but the algorithms that operate the vehicle, algorithms written by people (Bonnefon et al. 2016, Lin 2016, Yeomans 2014). The scenarios we need to examine already raise bafflingly complex issues and the individual elements that make up these scenarios offer almost infinite opportunities to discuss moral dilemmas, which touch upon areas of engineering, law, economics, philosophy and information technology. Adding to the importance of this issue is the fact that it is impossible to arrive at an all-embracing societal consensus on what is considered the favorable outcome of any given (dangerous) traffic situation (Holstein 2017).

Responsible innovation provides analytical and procedural principles that can be leveraged to generate solutions to begin addressing this immense challenge.

\section{Responsible Innovation: Addressing the Challenges}

Despite the promises and optimism surrounding autonomous vehicles, they raise a number of challenging issues and questions, and most respondents to public opinion surveys voice skepticism and concerns about these cars, pointing to potential problems with the widespread introduction, adoption, and use of the technology. way to achieve that is if developers move forward using tools and concepts associated with responsible research and innovation (RRI).

\subsection{Responsible Research and Innovation}

The concept of responsibility is not new in the process of research and innovation (Genus-Stirling 2018, Stilgoe et al. 2013); however, effective means of integrating responsibility in to all stages of R\&D and of achieving synergy between top-down mandatory and bottom-up voluntary efforts have been inadequate, as controversies 
around nuclear power and genetically modified agriculture have shown. Responsible research and innovation in today's sense appeared in the United States at the beginning of the 21st century and was adopted by the European Union a few years later (Fisher-Rip 2013). Since the roots of RRI are found in management, technology assessment, science and technology studies, and other areas (Inzelt-Csonka 2014, Owen et al. 2012), the concept has several definitions suggestive of its multidisciplinary origin (Buzás-Lukovics 2015, Chorus et al. 2012, Owen et al. 2012, Fisher-Rip 2013, Sutcliffe 2013, Tihon-Ingham 2011). A common feature found in all definitions is social responsibility, but each definition emphasizes environmental, ethical and political responsibility differently, and only a few definitions address the importance of open, transparent and accountable research and innovation (BuzásLukovics 2015, de Campos et al. 2017).

Despite this diversity, the definition of von Schomberg (2011, p. 60) appears to be the most widely accepted, thus we shall also use this definition in our study. According to this definition, RRI "is a transparent, interactive process by which societal actors and innovators become mutually responsive to each other with a view to the (ethical) acceptability, sustainability and societal desirability of the innovation process and its marketable products (in order to allow a proper embedding of scientific and technological advances in our society)." Thus, RRI delegates an important role to cooperation between the actors of innovation. In responsible innovation it is not enough to provide solutions concerning the product itself; it is also important to consider the research process and issues affected by the goals (Stilgoe et al. 2013).

To examine whether a certain research and development or innovation project (including its processes) accords with the principles of responsible innovation or not, the following four dimensions of responsible innovation offer a clear starting point (Buzás-Lukovics 2015, Carbajo-Cabeza 2018, Owen et al. 2012, Stilgoe et al. 2013):

1. Anticipation refers to the need for researchers and developers to constantly think about both known and yet unknown, but potential adverse effects, with questions like "What if?" in mind. Taking uncertainty, complexity and contingency in mind significantly increases our ability to identify and mitigate potential societal risks and harms.

2. Reflexivity examines the assumptions that limit technical experts' ability to identify and anticipate possible repercussions of their decisions, objectives, and motivations. In essence, it provides a mirror for the research process.

3. Inclusion refers to genuinely listening not only to the opinion of direct stakeholders, but to that of diverse and wider publics - whether through large or local public forums and discussions.

4. Responsiveness is closely related to the previous three items but has to do with taking actions that take into account during $R \& D \& I$ processes the values, concerns and opinions of diverse stakeholders regarding hazards and risks by adjusting the course of research, development and commercialization accordingly. 
In addition to these procedural principles that can help both scientific and industrial actors identify and integrate stakeholder values into their technical processes, the European Commission has also listed six key elements of responsible innovation (RRI keys) (EC 2014), which overlap to some extent with the aforementioned dimensions and can also help guide the process toward the practical implementation of RRI:

1. Public engagement in innovation ensures wider acceptance of outputs and more effective ways to tackle the urgent societal challenges. This practically refers to the dimension of inclusion.

2. Gender equality aims to improve the opportunities of women and the underrepresentation of women researchers, which is closely related to the dimensions of reflexivity and responsiveness.

3. Scientific education aims to broaden the knowledge of future researchers and other societal actors, so that they are able to participate more fully and actively in the innovation processes (including participating in public engagement). This key also stresses the importance of nurture creativity in children at the lowest possible age and to awaken and maintain their curiosity towards natural sciences in order to promote innovation in society.

4. Ethics: respect and adherence to shared values of the European Union (basic human rights and ethical standards) are key aspects for European understandings of responsible innovation, which influence how the dimensions of anticipation and responsiveness are applied.

5. Open access seeks to ensure the availability of research results to everyone. This key seeks to catalyze innovation but also to prepare a variety of stakeholders, experts and societal actors for informed participation in the innovation processes.

6. Governance: both the formal regulatory environment and the informal interactions among innovation actors greatly influences the outcomes of innovation processes and therefore can make the final difference in terms of whether these outcomes harmonize with the RRI dimensions of responsiveness and reflexivity.

These six key elements have shifted the emphasis towards the practical implementation of RRI, and the EU is also committed to integrate RRI into the daily activity of research institutes (Arnaldi et al. 2015, Forsberg et al. 2015). During our research we have found no analysis regarding the possibilities of integrating the concept of responsible innovation into a concrete example of (radical) innovation that is already under testing. Therefore, the autonomous vehicle as an example of radical innovation is an exceptional example and therefore, in the following section, we shall study how it can become an example of responsible innovation. 


\subsection{Tailoring Responsible Innovation to Address the Challenges of Autonomous Cars}

Based on the above, fully autonomous vehicles (on Level 5 automation) are currently defined as innovation outputs that are highly significant for humankind according to predictions and may also bring about considerable change.

We construct a framework for addressing the specific challenges facing autonomous vehicles described in Chapter 3 based on the RRI keys and dimensions (see Table 1). It is clear that tackling each challenge requires multiple keys and dimensions. For instance, the challenge of societal division towards autonomous cars can be addressed by the inclusion of society and providing information in a transparent manner to members of the public, scientific education and open access to research results. Anticipation, inclusion and reflexivity are key dimensions for this challenge. This approach also indicates that undertaking an R\&D project or innovation in a responsible manner requires a complex attitude and a complex set of tools with an important role of the interdisciplinary approach mentioned above.

Table 1 Managing the challenges of autonomous cars using RRI keys and dimensions

\begin{tabular}{|c|c|c|c|}
\hline Challenges of Self-Driving Cars & RRI Key & Dimension & Recommended Action \\
\hline $\begin{array}{l}\text { - Societal division } \\
\text { - Lack of information and trust in } \\
\text { Level } 5 \text { automation } \\
\text { - Fear of immature technology and } \\
\text { influence by extreme weather } \\
\text { - Uncertainty of medium and long- } \\
\text { term impacts on society }\end{array}$ & $\begin{array}{l}\text { 1. Public engagement } \\
\text { 2. Gender equality } \\
\text { 3. Scientific education } \\
\text { 5. Open access }\end{array}$ & \multirow{4}{*}{$\begin{array}{l}\text { 1. Anticipation } \\
\text { 2. Inclusion } \\
\text { 3. Reflexivity } \\
\text { 4. Responsiveness }\end{array}$} & $\begin{array}{l}\text { Consideration of } \\
\text { societal aspects in daily } \\
\text { decisions by } R \& D \& I \\
\text { innovators } \\
\text { High levels of } \\
\text { transparency and } \\
\text { providing information }\end{array}$ \\
\hline $\begin{array}{l}\text { - Uncertainty of medium and long- } \\
\text { term impacts on the environment }\end{array}$ & $\begin{array}{l}\text { 1. Public engagement } \\
\text { 4. Ethics }\end{array}$ & & $\begin{array}{l}\text { Consideration of } \\
\text { environmental aspects in } \\
\text { daily decisions by } \\
\text { R\&D\&I Innovators and } \\
\text { in supply chains }\end{array}$ \\
\hline $\begin{array}{l}\text { - Problems caused by system } \\
\text { failures } \\
\text { - Hacker attack, data privacy }\end{array}$ & $\begin{array}{l}\text { 1. Public engagement } \\
\text { 2. Gender equality } \\
\text { 4. Ethics } \\
\text { 5. Open access } \\
\text { 6. Governance }\end{array}$ & & $\begin{array}{l}\text { High levels of } \\
\text { transparency and } \\
\text { providing information } \\
\text { Engagement of } \\
\text { stakeholders }\end{array}$ \\
\hline $\begin{array}{l}\text { - The effect of interaction with } \\
\text { other traffic partners } \\
\text { - The "decisions" of cars in } \\
\text { emergency situations } \\
\text { - Uncertainty of medium and long- } \\
\text { term ethical impacts }\end{array}$ & 4. Ethics & & $\begin{array}{l}\text { Consideration of ethical } \\
\text { aspects in daily decisions } \\
\text { by R\&D\&I innovators }\end{array}$ \\
\hline $\begin{array}{l}\text { - Immaturity of the regulatory } \\
\text { environment } \\
\text { - Uncertainty regarding legal } \\
\text { liability }\end{array}$ & 6. Governance & $\begin{array}{l}\text { 1. Anticipation } \\
\text { 2. Inclusion } \\
\text { 3. Reflexivity } \\
\text { 4. Responsiveness }\end{array}$ & Governance, control \\
\hline
\end{tabular}

Source: own construction 
Once the key elements and dimensions in Table 1 are identified, we can recommend concrete measures to tackle most of the challenges related to the introduction of autonomous vehicles with the help of responsible innovation criteria. These recommendations are as follows:

1. We must regard R\&D\&I decisions of researchers and innovators as key factors in the practical implementation of responsible innovation. It is important to note that this does not only apply to key strategic decisions, but also to all small and seemingly insignificant decisions made during everyday R\&D\&I tasks. The challenge in the factor of decisions lies in the fact that during R\&D\&I processes related to autonomous vehicles it is usually people with a technical and scientific mindset who make technical-scientific decisions, with unusually far-reaching impacts that - based on the above point well beyond the realms of engineering and natural sciences. Therefore, there is a need for the integration of social sciences into decision-making, which may be achieved by many methods including widely accepted methods such as Socio-Technical Integration Research (STIR).

2. Given that the matter of concern is a radical innovation with the potential to influence wide segments of the populations of industrialized societies, particular attention must be focused on transparency, and continuous and accurate public information. Since the public to be informed is extremely heterogeneous, their media consumption also ranges across a wide variety of channels. This must be kept in mind when planning a communication strategy, considering that those supportive of and skeptical of autonomous vehicles are not simple binary and opposing groups but can comprise the same social groups.

3. Early understanding and integration of the needs and values of all stakeholders is also paramount and provides the basis for an optimal balance of key values (e.g. sustainability, safety, ethics, transparency) in the stages of planning. Since concern is a natural, inherent factor present in the tough questions raised in relation to radical innovations, addressing these concerns responsibly is indispensable.

4. The three steps described above reflect a bottom-up approach; however, in our view, a top-down approach is also important: to create a regulatory environment that provides for the integration of the elements of responsible innovation (e.g. societal, ethical and environmental impacts) and also creates the opportunity (provides for) multiple feed-back, to ensure that research and development processes and innovation truly result in socially important outputs.

Based on the above, two important aspects must be considered for responsible innovation to succeed, which, at the same time, also provide the basis for intervention:

- An interdisciplinary approach, which promotes collaboration among engineers, social scientists, policymakers and public stakeholders to shape future directions for technological development. 
- Anticipatory analysis at an early stage of technical planning when a wider range of opportunities for planning are still available, thus technical development can easily be modified.

We must emphasize that the application of the framework of responsible innovation is not a panacea; no single framework will be able to tackle all challenges automatically. It will, however, be able to handle a significant proportion of challenges effectively (Figure 1), if the implementation of the recommended steps is based on an interdisciplinary approach and the necessary but not sufficient conditions of a proactive mindset; and if all stakeholders actively participate in the process rather than passively following it.

Figure 1 The logical framework of autonomous cars and responsible innovation

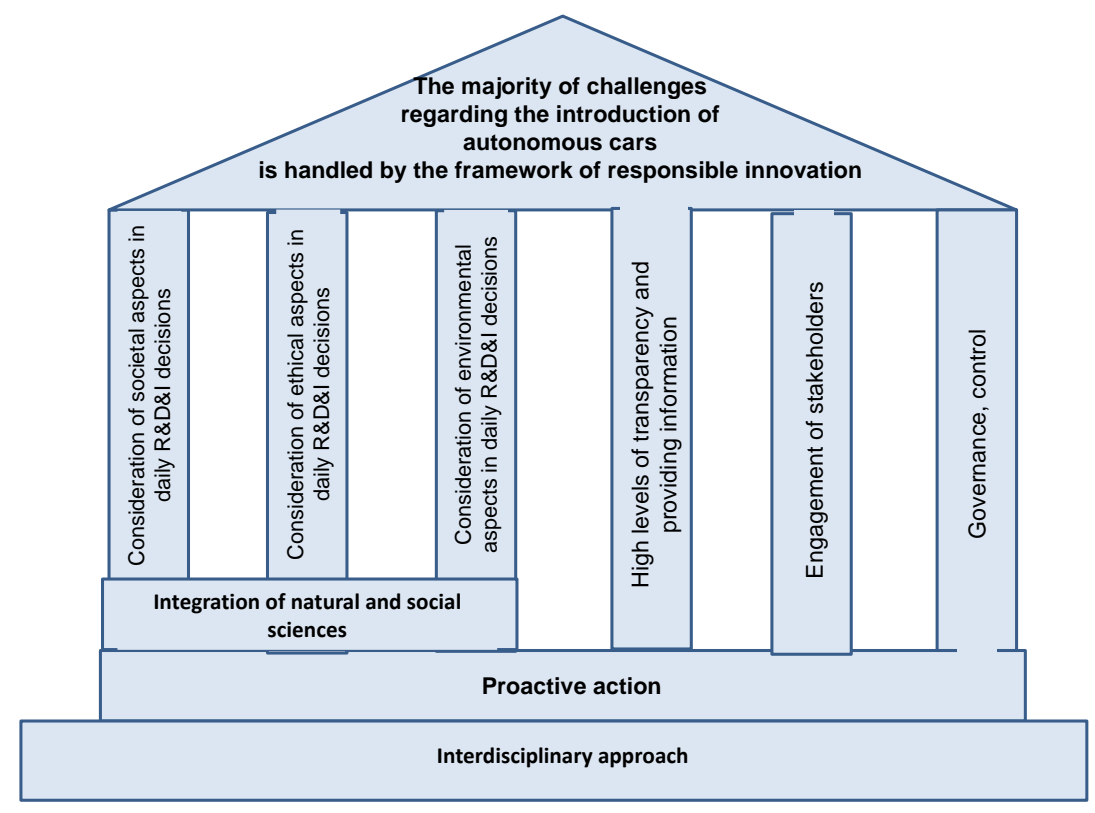

Source: own construction

\section{Summary}

The development of autonomous vehicles is in a far more advanced stage than many in the general public may think citizens in 73 cities may already encounter autonomous vehicles regularly in traffic in their cities; moreover, they may even use these vehicles as participants in final-phase tests. According to predictions, autonomous vehicles may, in many cases, bring about radical changes in the lives of everyday people.

However, a host of questions still lack satisfactory answers, and there are numerous risks that are recognized by public opinion on autonomous vehicles. In theory, such concerns may be successfully managed if the development of autonomous vehicles moves forward with the framework of responsible innovation, thereby reducing the probability of potential unintended future adverse effects. 
The dimensions and keys of responsible innovation suggest a framework in which the concrete activities that may help reduce risks and find satisfying solutions to questions still open can be provided. We must take R\&D\&I decisions of researchers and innovators into consideration as key factors in the practical implementation of responsible innovation, with particular regard to the societal, ethical and environmental aspects of those decisions. This effort is efficiently enhanced by the integration of natural and social sciences. Special attention must also be focused on transparency, and continuous and accurate publicly available information; on the early understanding and integration of the needs and values of all stakeholders; and on the creation of a flexible and supportive regulatory environment. An interdisciplinary approach and proactivity are necessary but not sufficient conditions for all these.

We must note that the application of the framework of responsible innovation will not be able to tackle all challenges automatically. However, this framework may prove able to handle a significant proportion of challenges effectively and efficiently, if the recommended steps are implemented with the active participation of all stakeholders in the process.

\section{References}

AAA (2017): Vehicle Technology Survey. Washington: Automotive Engineering. Arbib, J. - Seba, T. (2017): Rethinking Transportation 2020-2030: The Disruption of Transportation and the Collapse of the Internal-Combustion Vehicle and Oil Industries. A RethinkX Sector Disruption Report, May 2017.

Arnaldi, S. - Quaglio, G. - Ladikas, M. - O'Kane, H. - Karapiperis, T. - Srinivas, K. R. - Zhao, Y. (2015): Responsible governance in science and technology policy: Reflections from Europe, China and India. Technology in Society, 42, 81-92.

Blyth, P. L. - Mladenovic, M. N. - Nardi, B. A. - Su, N. M. - Ekbia, H. R. (2015): Driving the Self-Driving Vehicle. Expanding the Technological Design Horizon. 2015 IEEE International Symposium on Technology and Society (ISTAS). Dublin, Ireland.

Bonnefon, J. F. - Shariff, A. - Rahwan, I. (2016): The Social Dilemma of Autonomous Vehicles. Science, 352, 6293, 1573-1576.

Buzás, N. - Lukovics, M. (2015): A felelősségteljes innovációról. Közgazdasági Szemle, 62, 4, 438-456.

Capgemini (2011): Digital Transformation Review. The Challenges of the Digital Revolution. Capgemini Consulting.

Carbajo, R. - Cabeza, L. F. (2018): Renewable energy research and technologies through responsible research and innovation looking glass: Reflexions, theoretical approaches and contemporary discourses. Applied Energy, 211, 792-808.

Chorus, C. - van Wee, B. - Zwart, S. (2012): TPM Catalogue. Concepts, Theories, Methods. Delft University of Technology, Delft.

Cunneen, M. - Mullins, M. - Murphy, F. (2019): Autonomous Vehicles and Embedded ArtificialIntelligence: The Challenges of Framing Machine Driving Decisions. Applied Artificial Intelligence, 33, 706-731. 
Davies, R. (2015): Industry 4.0. Digitalisation for Productivity and Growth. Briefing. European Parliamentary Research Service, Brussels, Belgium.

de Campos, A. S. - Hartley, S. - de Koning, C. - Lezaun, J. - Velho, L. (2017): Responsible Innovation and political accountability: genetically modified mosquitoes in Brazil. Journal of Responsible Innovation, 4, 5-23.

EC (2014): Responsible Research and Innovation. Europe's ability to respond to societal challenges. Brussels: European Commission.

Fagnant, D. J. - Kockelman, K. (2015): Preparing a Nation for Autonomous Vehicles: Opportunities, Barriers and Policy Recommendations. Transportation Research Part A, 77, 167-181.

Fisher, E. - Rip, A. (2013): Responsible Innovation: Multi-Level Dynamics and Soft Intervention Practices. In Owen, R. - Bessant, J. - Heintz, M. (eds.): Responsible innovation: Managing the responsible emergence of science and innovation in society. John Wiley \& Sons, Ltd., Hoboken, NJ, USA, 165-183.

Forsberg, E-M. - Quaglio, G. - O'Kane, H. - Karapiperis, T. - von Woensel, L. Arnaldi, S. (2015): Assessment of science and technologies: Advising for and with responsibility. Technology in Society, 42, 21-27.

Genus, A. - Stirling, A. (2018): Collingridge and the Dilemma of Control: Towards responsible and accountable innovation. Research Policy. 47, 1, 61-69.

Giffi, C. - Vitale, J. - Robinson, R. - Pingitore, G. (2017): The Race to Autonomous Driving: Winning American Consumers' Trust. Deloitte Review, 20, 73-93.

Glancy, D. J. (2015): Autonomous and Automated and Connected Cars-Oh My! First Generation Autonomous Cars in the Legal Ecosystem. Minnesota Journal of Law, Science \& Technology, 16, 2, 619-691.

Goorden, L. - van Oudheusden, M. - Evers, J. - Deblonde, M. (2008): Nanotechnologies for Tomorrow's Society: A case for reflective action research in Flanders, Belgium. In Fisher E. - Selin C. - Wetmore J.M. (eds.): Presenting Futures. The Yearbook of Nanotechnology in Society, Vol. 1. Springer, Dordrecht.

ITF (2015): Automated and Autonomous Driving: Regulation under Uncertainty. International Transport Forum Policy Papers, No. 7. OECD Publishing, Paris.

Hohenberger, C. - Spörrle, M. - Welpe, I. M. (2016): How and why do men and women differ in their willingness to use automated cars? The influence of emotions across different age groups. Transportation Research Part A, 94, 374-385.

Holstein, T. (2017): The Misconception of Ethical Dilemmas in Self-Driving Cars. In Dodig-Crnkovic, G. (ed.): Proceedings of the Summit of the International Society for the Study of Information on Digitalisation for a Sustainable Society: Embodied, Embedded, Networked, Empowered through Information, Computation \& Cognition. Gothenburg, Sweden.

Hwang, J. S. (2016): The Fourth Industrial Revolution (Industry 4.0): Intelligent Manufacturing. Researchgate Publications.

Inzelt, A. - Csonka L. (2014): Responsible Science in Societies. In Buzás, N. - Lukovics, M. (eds.): Responsible innovation. University of Szeged, Szeged, 57-72. 
Kagermannm H. - Anderl, R. - Gausemeier, J. - Schuh, G. - Wahlster, W. (2016): Industrie 4.0 in a Global Context: Strategies for Cooperating with International Partners. Acatech Study, Munich, Germany.

Keeney, T. (2017): Mobility-As-A-Service: Why Self-Driving Cars Could Change Everything. Research White Paper. ARK Invest, New York, NY, USA.

Kennedy, J. (2008): Nanotechnology: the future is coming sooner than you think. Springer, Dordrecht.

Kovács, O. (2017a): Az ipar 4.0 komplexitása - I. Közgazdasági Szemle, 56, 7, 823-851.

Krishna, S. (2017): Enhancing Academic Outcome Through Digitalization. ResearchGate Publications.

Kyriakidis, M. - Happee, R. - de Winter J.C.F. (2015): Public opinion on automated driving: Results of an international questionnaire among 5000 respondents. Transportation Research Part F, 32, 127-140.

Kuruczleki, É. - Pelle, A. - Laczi, R. - Fekete, B. (2016): Doing Business in the EU under the fourth industrial revolution: Challenges ahead of knowledgeintensive economic actors. In Dermol, V. - Trunk, A. - Smrkolj, M. (eds.): Managing Innovation and Diversity in Knowledge Society Through Turbulent Time. Proceeding MakeLearn and TIIM Joint International Conference, Timisoara.

Lengyel, I. - Szakálné, K. I. - Vas, Zs. - Lengyel, B. (2016): Az újraiparosodás térbeli kérdőjelei Magyarországon. Közgazdasági Szemle, 63, 6, 615-646.

Lin, P. (2016): Why Ethics Matters for Autonomous Cars. In Maurer, M. - Gerdes, J. C. - Lenz, B. - Winner, H. (eds.): Autonomous Driving. Technical, Legal and Social Aspects. SpringerOpen, 69-85.

Litman, T. (2017): Autonomous Vehicle Implementation Predictions. Implications for Transport Planning. Victoria Transport Policy Institute, Victoria, BC.

Nagy, J. (2017): Az ipar 4.0 fogalma, összetevői és hatása az értékláncra. 167. sz. Múhelytanulmány. Budapesti Corvinus Egyetem Vállalatgazdaságtan Intézet, Budapest.

Nascimento, A. M. - Vismari, L. F. - Molina, C. B. S. T - Cugnasca, P. S. - Camargo Jr., J. B. - de Almeida Jr., J. R. - Inam, R. - Fersman, E. - Marquezini, M. V. - Hata, A. Y. (2019): A Systematic Literature Review about the impact of Artificial Intelligence on Autonomous Vehicle Safety. IEEE Transactions on Intelligent Transportation Systems.

OECD (2015): Identifying and Inducing Breakthrough Inventions: An Application Related to Climate Change Mitigation. OECD Science, Technology and Industry Working Papers 2015/4. OECD, Paris.

OECD (2019): Artificial Intelligence in Society. OECD, Paris.

OW (2014): Digital Revolution. New Customer Experiences, New Business Models, New Transformations. Oliver Wyman, March and McLennan Companies.

Owen, R. - Macnaghten, P. - Stilgoe, J. (2012): Responsible research and innovation: from science in society to science for society, with society. Science and Public Policy, 39, 6, 751-760. 
Pfohl, H. C. - Yahsi, B. - Kurnaz, T. (2015): The Impact of Industry 4.0 on the Supply Chain. In Kersten, W. - Blecker, T. - Ringle, C. M. (eds.): Innovations and Strategies for Logistics and Supply Chains. Technologies, Business Models and Risk Management. Proceedings of the Hamburg International Conference of Logistics (HICL).

Prisecaru, P. (2016): Challenges of the fourth industrial revolution. Knowledge Horizons - Economics, 8, 1, 57-62.

Schmidt, R. - Möhring, M. - Härting, R. C. - Reichstein, C. - Neumaier, P. Jozinovic, P. (2015): Industry 4.0 - Potentials for Creating Smart Products: Empirical Research Results. In Abramowicz, W. (ed.): Business Information Systems. 18th International Conference, BIS 2015, Poznan, Poland, 16-27.

Schoettle, B. - Sivak, M. (2014): A Survey of Public Opinion about Autonomous and Self-Driving Vehicles in the US, the UK, and Australia. The University of Michigan, Ann Arbor, MI.

Schuh, G. - Anderl, R. - Gausemeier, J. - Ten Hompel, M. - Wahlster, W. (2017): Industrie 4.0 Maturity Index. Managing the Digital Transformation of Companies. Acatech Study, Munich, Germany.

Smit, J. - Kreutzer, S. - Moeller, C. - Carlberg, M. (2016): Industry 4.0. Study for the ITRE Committee. European Parliament Directorate General for Internal Policies, Brussels.

SMMT (2017a): Connected and Autonomous Vehicles. Revolutionising Mobility in Society. The Society of Motor Manufacturers and Traders, London.

SMMT (2017b): Connected and Autonomous Vehicles. Position Paper. The Society of Motor Manufacturers and Traders, London.

Stilgoe, J. - Owen, R. - Macnaghten, P. (2013): Developing a framework for responsible innovation. Research Policy, 42, 9, 1568-1580.

Sutcliffe, H. (2013): A Report on Responsible Research and Innovation. Matter, London.

Tihon, A. - Ingham, M. (2011): The societal system and responsible innovations: Freeing sustainable development from a deadlock. Journal of Innovation Economics, 2, 8, 11-31.

Wadud, Z. - MacKenzie, D. - Leiby, P. (2016): Help or hindrance? The travel, energy and carbon impacts of highly automated vehicles. Transportation Research Part A, 86, 1-18.

von Schomberg, R. (2011): Prospects for technology assessment in a framework of responsible research and innovation. In Beecroft, M. - Dusseldorp, R. (eds.): Technikfolgen Abschätzen Lehren: Bildungspotenziale Transdisziplinärer. Vs Verlag, Wiesbaden, 39-61.

Yap, M. D. - Correia, G. - van Arem, B. (2016): Preferences of travellers for using automated vehicles as last mile public transport of multimodal train trips. Transportation Research Part A, 94, 1-16.

Yeomans, G. (2014): Autonomous Vehicles. Handing Over Control: Opportunities and Risks for Insurance. Lloyd's, London. 